\title{
REGIONALIZAÇÃO E DESENVOLVIMENTO ECONÓMICO DAS REGIÕES QUE TEMOS ÀS REGIÕES - PROJECTO
}

\author{
Alfredo Simões
}

\begin{abstract}
O presente artigo justifica a intervenção do Estado no âmbito da política regional. No entanto, considerando que esta política centralizada tem falhado, é necessário desenvolver uma perspectiva mais territorializada, centrada a partir dos diferentes espaços geográficos, que promova uma organização mais eficiente e um melhor aproveitamento dos recursos locais.

Por outro lado, as consequências da globalização das economias exigem respostas mais flexiveis e menos dependentes da autoridade única do Estado. A Regionalização, ao proporcionar a criação de "Regiões-projecto", poderá dar resposta a estes novos desafios e, assim, desenvolver a competitividade de cada um dos territórios do espaço nacional.
\end{abstract}

A Regionalização é um processo cujo debate reclama a existência de três vertentes fundamentais: a política, a administrativa e a da cidadania. A consideração destas vertentes deverá ser conjunta, não esquecendo qualquer delas, sob o risco de se transformar num processo meramente tecnocrático ou de puro oportunismo político. O que está em causa é a descentralização do poder do Estado para órgãos políticos com esferas de acção diferenciadas; é a reorganização da máquina administrativa do Estado que deverá dar suporte à

- Professor Adjunto da Escola Superior de Tecnologia do Instituto Politécnico de Viseu. Director do Departamento de Gestão. 
descentralização política; é o aumento das oportunidades de participação dos cidadãos na vida pública, na definição de objectivos e projectos colectivos e na resolução dos problemas comuns.

Nestas circunstâncias, a Regionalização deverá ser um instrumento ao serviço do desenvolvimento, entendido como a possibilidade da economia e da sociedade proporcionarem às pessoas - onde quer que elas vivam - iguais oportunidades de acesso aos bens e serviços disponíveis para satisfação das suas necessidades. Em consequência, e retomando conceitos há muito defendidos e generalizadamente aceites, para esta definição concorrem duas ideias-chave fundamentais: a primeira é a de que o desenvolvimento pressupõe o crescimento, isto é, a produção continuada de bens e serviços de uma economia e, por outro lado, "todo o desenvolvimento tem de ser desenvolvimento regional" (Lopes, 1980).

\section{POLÍTICA REGIONAL - A NECESSÁRIA INTERVENÇÃO DO ESTADO}

$\mathrm{Na}$ realidade, o crescimento económico dos países tem provocado e aprofundado disparidades regionais, quer ao nível do rendimento per capita, quer ao nível do emprego. No nosso país, em particular, são conhecidas as diferenças entre algumas regiões do litoral, com mais emprego industrial e de serviços, com maior poder de compra, etc. e as regiões do interior, mais pobres, menos dotadas em infra-estruturas, mais dependentes das actividades agrícolas, quantas vezes de subsistência.

A verdade, porém, é que a economia portuguesa cresceu, a riqueza nacional e per capita tem vindo a aumentar, em suma, cada português, hoje, vive melhor do que, por exemplo, há 30 anos atrás. Esta situação de crescimento económico, por um lado, e de intensificação das assimetrias regionais, por outro, não é exclusiva de Portugal, antes abrange todos os países europeus e ocidentais onde funcionam os mecanismos de mercado. Mesmo a ex-URSS e as democracias populares de leste, recentemente desaparecidas, sofreram - e parece que sem remédio eficaz - dos mesmos desequilíbrios.

O crescimento económico é, pois, gerador de situações de desigualdade que se manifestam claramente ao nível espacial. A criação $e$ desenvolvimento de políticas sectoriais, assumidas pelos Estados nacionais para servirem o crescimento, representam, assim, fontes de disparidades na localização das actividades económicas e das pessoas, bem como dos 
rendimentos, ou seja, sendo necessárias, não servem, na plenitude, objectivos de desenvolvimento, tal como os definimos anteriormente.

Desta forma, e sendo estes desequilíbrios socialmente inaceitáveis, encontramos justificação para a intervenção do Estado no âmbito do que podemos designar como Política Regional.

Numa economia de mercado, o papel regulador cabe, por excelência, ao mercado. A definição do que é produzido, dos processos utilizados, etc. resultam dos mecanismos das leis da oferta e da procura e os factores produtivos - capital e trabalho - deslocam-se de um lugar para outro de acordo com a remuneração que desejam obter. Ao Estado competirá remover obstáculos e auxiliar a clarificação das regras do jogo. Porém, a teoria económica aceita a intervenção do Estado em situações particulares, nomeadamente ao abrigo do chamado argumento das indústrias nascentes.

$\mathrm{Na}$ mesma lógica, autores defendem a intervenção do Estado protegendo regiões que se encontram em dificuldades no processo de desenvolvimento. Também nestes casos a intervenção dos poderes públicos deverá ser temporária e os benefícios esperados deverão compensar os prejuízos decorrentes de qualquer intervenção no mercado ${ }^{2}$.

Os exemplos conhecidos mostram que as formas de que se revestem estas intervenções têm evoluído ao longo dos anos e variam de país para país. No entanto, genericamente, a aç̧ão do Estado, no âmbito daquilo a que poderemos designar por política regional, tem-se dirigido à criação de incentivos, à localização das actividades económicas (incentivos fiscais, subsídios ao emprego, criação de infra-estruturas - parques industriais, etc.) ou à simples transferência de rendimentos para as regiões menos desenvolvidas ${ }^{3}$. Com estas medidas, a acção do Estado visa atingir dois objectivos: a) maior equidade na distribuição dos rendimentos entre as pessoas, independentemente do lugar onde vivem; e b) criação de meios nas regiões com problemas, de forma a que estas possam melhor aproveitar os recursos endógenos que o mercado, por si so, não foi capaz de fazer. A prossecução destes objectivos concorre para uma melhor gestão política das desigualdades sociais e também para um aproveitamento mais eficiente dos recursos nacionais.

Estas medidas não estão isentas de críticas. Com efeito, na perspectiva das teorias neo-clássicas, esta intervenção do Estado torna mais difíceis os movimentos de ajustamento das economias apoiadas e, por outro lado, cria-se aquilo que se designa de sindroma da dependência: uma população habituada a viver da generosidade do Estado, indústrias que esperam ser subsidiadas pelo Estado e autarquias regionais que dependem do Estado central para desencalhar os seus orçamentos (Polèse, 1998). 
Para além das objecções de natureza teórica, é certo que esta intervenção do Estado, centralizada e dirigista, tem-se mostrado insuficiente para resolver os problemas das desigualdades regionais. Por isso, principalmente desde os anos 80 que se olha para as questões da política regional, não apenas do ponto de vista do poder central mas principalmente segundo a perspectiva da região, dos espaços onde se localizam as actividades económicas e são sujeitos das intervenções exteriores (do Estado ou outras - empresas, etc.) e da acção dos agentes internos.

\section{UMA NOVA PERSPECTIVA PARA A POLÍTICA REGIONAL}

A questão do desenvolvimento regional não é apenas uma função do Estado central mas é também, e em larga medida, um objectivo de cada região. As políticas de desenvolvimento regional devem contar, assim, com outros actores, as autarquias e instituições locais, capazes de se apoiarem nas dinâmicas internas (organizá-las ou mesmo qualificá-las) e nos recursos próprios para construírem o seu processo de desenvolvimento económico. Alguns temas e argumentos deste "modelo alternativo", de desenvolvimento poderemos encontrá-los sistematizados em Polèse (1998: 218):

- falhanço das políticas nacionais e a insatisfação criada pelas políticas tradicionais de desenvolvimento regional;

- a necessidade de um maior respeito pelo espaço vivido;

- a crise da grande empresa e a importância das pequenas empresas e dos regionalismos;

- a importância renovada das relações não mediadas pelo mercado e da solidariedade social;

- a necessidade de novos mecanismos locais de intervenção e de ajustamento, face à globalização crescente do capital e de outros factores de produção.

Nas estratégias de desenvolvimento local costumam estar presentes aç̧ões que promovam o espírito de empresa (entrepreneurship) e que valorizem as dinâmicas colectivas, agregadoras dos agentes locais (autarquias, empresas, etc.) em projectos comuns, geradores de sinergias nos territórios onde ocorrem. São estratégias voluntaristas cujos resultados não surgiram a partir do simples funcionamento dos mecanismos de mercado.

Neste sentido, não se podendo falar em intervenção centralizada do Estado, esta não deixa de estar presente a outros níveis, mais próximos do 
local onde outros agentes - privados e públicos -, de âmbito geográfico infranacional, estabelecem a sua acção e concretizam as suas estratégias de desenvolvimento. O território nacional é, assim, um conjunto de vários territórios com os seus próprios recursos (natureza, pessoas, capital, informação), as suas actividades e agentes marcados pelas experiências vividas, pelas formas de inserção nos mercados e na sociedade (local, regional, nacional ou global) e de relacionamento diverso com outras regiões.

Esta nova abordagem das questões do desenvolvimento - centrada mais a partir do interior dos diferentes territórios - tem vindo a assumir um relevo crescente em desfavor - sem a excluir - da perspectiva centralizada na acção do Estado, geradora apenas de políticas redistributivas. É esta, também, a um nível supranacional, a perspectiva dominante na União Europeia, e muitos documentos da OCDE, dos últimos anos, reflectem igualmente esta abordagem da problemática do desenvolvimento.

O que se subentende desta perspectiva de desenvolvimento é que um dado território ${ }^{5}$ não é necessariamente idêntico ao território vizinho, assume-se na diversidade do território nacional em que se insere. No entanto, relaciona-se intensamente com um e com o outro e é capaz de responder, de forma individualizada, a situações concretas, motivadas a partir do seu exterior.

\section{A GLOBALIZAÇÃO E O(S) PODER(ES) DO ESTADO}

Outra questão merece ser reflectida: num contexto de integração económica no espaço europeu e, mais ainda, quando se assiste a uma rápida globalização da economia, acompanhada por mudanças tecnológicas radicais de difícil absorção, devido a dificuldades de ajustamento de formas organizativas e de estratégias de gestão a diversos níveis, neste contexto fará sentido a abordagem territorial do desenvolvimento, "desvalorizando" a perspectiva nacional centrada na autoridade do Estado?

Em rigor, não se pode falar em desvalorização do poder do Estado central sobre os diferentes territórios - até porque não estão em causa as funções fundamentais da autoridade do Estado - mas tão-só em novas formas descentralizadas de gestão das políticas de ordenamento e desenvolvimento do país.

O contexto mundial que referimos acima, caracterizado pela globalização das economias e pelas mudanças tecnologicas, é ele próprio motivador desta delegação de competências para os níveis infranacionais da administração do Estado. Com efeito, a turbulência a que assistimos tem provocado alterações 
significativas nos processos de produção (ganhando relevo a flexibilidade destes processos em detrimento da produção em massa); as deslocalizações das empresas ou de fragmentos dos processos produtivos têm vindo a inquietar algumas regiões, beneficiando outras que ofereçam mais vantagens (preços de factores, recursos, localização, qualificações de mão-de-obra, etc.); sectores inteiros, quer pela evolução tecnológica, quer pelo aparecimento de novos produtos têm conhecido ajustamentos profundos e gerado desemprego ou procura de novas qualificações profissionais, etc. Todas estas alterações se têm processado não sem que os seus efeitos se reflictam de forma diversa nos diferentes espaços geográficos. Com a globalização da economia - sempre associada a mudanças tecnológicas e a maior concorrência -, algumas áreas geográficas tornaram-se centros de inovação, internacionalizaram as suas actividades, qualificaram os recursos humanos; outras, porém, perderam dinâmica, ficaram para trás.

A flexibilidade introduzida na produção pelas novas tecnologias, associada (ou em resultado de) à individualização da procura, conduziu ao aparecimento de novos modos de produção e representa um desafio à evolução das formas organizativas e de gestão da sociedade. Ao Estado central, monolítico, correspondeu a produção em massa, uniformizada; hoje, perante as diferentes realidades no espaço nacional, um país não pode ter uma gestão sob o comando da perspectiva única, perdendo com isso a flexibilidade necessária para actuar de maneira diferente, consoante as diferenças das consequências sobre os territórios e de acordo com os objectivos que cada realidade ensina poderem vir a ser alcançados.

A perspectiva do Estado deve, pois, ser territorializada, isto é, aos grandes objectivos definidos para o todo nacional deverá acrescentar os objectivos e os projectos de cada realidade territorial. Esta nova perspectiva não enfraquece pois a autoridade do Estado, ao contrário, reforça-a mas também lhe traz outras responsabilidades.

Em documento recente da União Europeia ${ }^{6}$ é afirmado: "o rumo que o desenvolvimento económico, social e territorial da UE tomará a longo prazo será substancialmente afectado por três factores: a) as consequências da integração económica gradual da Europa e de uma cooperação política mais intensa entre os estados membros e destes com outras partes interessadas; b) o papel crescente das autoridades locais e regionais e da sua intervenção em matéria de desenvolvimento territorial; c) o alargamento provável da união e o desenvolvimento das relações com os seus vizinhos". Em consequência destas novas condições, o citado documento refere que três formas diferentes de interdependência afectarão a sociedade europeia: a) entre regiões; b) entre as diversas políticas sectoriais que têm impacto sobre 
uma determinada área; c) entre os diversos níveis de governo que partilham a responsabilidade por uma região específica.

Sem pretendermos analisar o documento ou a citação feita, parece-nos claro que ao Estado não poderão fugir, por um lado, as responsabilidades da política externa (quer no contexto bilateral, quer no contexto comunitário) e, por outro, a coordenação de políticas internas, nomeadamente ao nível das políticas sectoriais e de desenvolvimento territorial. Estas funções deverão ser, naturalmente, centralizadas. Porém, a primeira tarefa do Estado não poderá deixar de ser a sua própria organização interna.

Não se perceberia como é que, evoluindo a sociedade nos termos que sintetizámos acima, a administração do Estado se poderia manter estática (ao arrepio do que se passa por todos os países desenvolvidos) ou, quando muito, maquilhada sem alterar o essencial. Por isso, a delegação de competências para níveis inferiores da administração, como está subentendido no documento citado e como a evolução da sociedade recomenda pela diversificação das situações criadas, tem sido adoptada pelos países europeus e da OCDE.

\section{O PODER CENTRAL E A PROVÍNCIA. AS ALTERNATIVAS DE PODER}

Portugal não fugiu a esta regra, contudo, fê-lo com erros, com atraso, tímida e ao sabor de conveniências não assumidas politicamente. Até ao "25 de Abril" um Estado centralista dominou o país, não atribuindo competências relevantes às autarquias locais existentes e, cegamente, enquadrou-as com peias apertadas em termos administrativos e políticos. Malgrado esta visão estreita, em 1936 tinham sido criadas as Províncias, uma autarquia intermédia entre o poder central e os municípios enfraquecidos, mas que nunca tiveram competências definidas. A sorte estava traçada e, vinte e três anos depois, desapareciam. Os Distritos serviam como instrumento da autoridade central na "província" e esta não necessitava de orgãos de poder. Porém, em finais dos anos 60 , era evidente a desigual distribuição da riqueza e da população do país e estas preocupações levaram à criação das regiõesplano. Sem qualquer legitimidade, salvo a que lhes advinha da sua natureza desconcentrada da administração do Estado, estes organismos acabaram por sofrer da insuficiência de que padeceu a execução do III Plano de Fomento que os fundamentava.

Dez anos depois, em plena fase de consolidação do regime democrático, e com alguns ajustamentos, as regiões-plano deram origem às cinco comissões 
de coordenação regional que ainda hoje se mantêm. Apesar dos meios e das competências que se lhes reconhecem, três questões continuam por resolver na sociedade portuguesa: a) a coordenação dos serviços desconcentrados do Estado nos diferentes territórios não existe $^{7}$; b) as competências das autarquias locais continuam aquém do desejável e do que é norma nos países desenvolvidos; e c) as regiões continuam sem voz, sem projecto e sem órgãos legítimos para a promoção do seu desenvolvimento ${ }^{8}$.

As economias nacionais podem ser adversamente afectadas pela reestruturação de um ou outro sector, mas as regiões tomadas individualmente podem ser devastadas por tais mudanças. Perante uma situação destas, faz sentido que a região, sem órgãos políticos de decisão, sem orçamento próprio que possa gerir, esteja à espera de uma acção concertada do governo sediado no Terreiro do Paço? A rigidez de uma tal solução não se coaduna com as mudanças rápidas que moldam o mundo de hoje e desarma as próprias regiões que têm de competir num quadro global, muito para além do simples território nacional.

Poderiam as autarquias locais existentes constituir-se em substituto perfeito de um órgão de natureza regional? Cada uma de per si não tem dimensão geográfica suficiente para que a decisão tomada se torne eficaz. Porém, poder-se-á pensar em associações de municípios como forma de ultrapassar esse obstáculo. Não devemos contudo esquecer que essas associações, sendo relevantes para a concretização de objectivos específicos ${ }^{9}$, representam legitimidades políticas com perspectivas diferenciadas para $o$ desenvolvimento da região, as quais não resultaram de um processo electivo em que o povo tenha sido chamado a sufragar projectos comuns que queira ver concretizados. Sendo importantes, as associações de municípios estão politicamente limitadas na sua acção.

Por outro lado, a experiência portuguesa dos últimos 20 anos tem evidenciado que organismos de cariz essencialmente técnico, como as comissões de coordenação regional, mesmo que desenvolvam - como devem acções de promoção do potencial das regiões, estão sempre limitadas na sua função de representação - junto do poder central ou junto de organismos internacionais ou de outras regiões vizinhas (nacionais ou estrangeiras) porque, de facto, lhes falta a capacidade política necessária ao exercício dessa função.

Em suma, as alternativas que o país tem procurado promover não se têm assumido como verdadeiros substitutos de um poder que deve ser exercido a um nível intermédio, capaz de promover o desenvolvimento do potendial das regiões, representativo da vontade das populações e autêntico interlocutor e organizador dos interesses particulares e locais junto do poder central. É este, afinal, o papel dos órgãos intermédios da administração na generalidade 
dos países europeus que colmata as insuficiências da intervenção única e centralizada do Estado e procura dinamizar, qualificar e dar visibilidade às iniciativas de desenvolvimento das populações locais junto do poder central.

\section{5. "REGIÕES-SINDICATO" OU "REGIÕES-PROJECTO"?}

A Regionalização, ao criar órgãos de decisão intermédios, torna o aparelho administrativo mais eficiente - porque permite que o governo central se concentre apenas nas tarefas "nacionais" do exercício do poder - e aproxima, no tempo e no espaço, a tomada de decisão dos problemas a resolver e dos agentes que se confrontam com esses mesmos problemas.

Por outro lado, a perspectiva da Regionalização, para além de permitir organizar a máquina do Estado, de promover a redefinição eficaz das funções de cada esfera do poder e de contribuir para o exercício dos direitos de cidadania dos portugueses, permitirá que o país tenha "regiões-projecto", em vez das actuais "regiões-sindicato", facilitará o planeamento com vista ao desenvolvimento económico, coordenando nos diferentes territórios a aplicação das várias políticas sectoriais.

Quando hoje falamos na inserção das economias - e em particular da economia portuguesa - nos mercados internacionais ou no mercado global, certamente que esta realidade é percepcionada de maneira diferente pela região de Lisboa, pelo Grande Porto ou pelo Alentejo ou Trás-os-Montes. Não se trata apenas (ou principalmente) de analisar o problema sob o ponto de vista de um sector ou de algumas empresas mais avançadas no processo de globalização, enquanto outros ainda não conseguiram criar condições para competirem abertamente nos mercados. Compreende-se que, no conjunto da economia nacional, haja algumas unidades produtivas mais avançadas do que outras, mais competitivas do que outras, com ritmos de crescimento diferenciados. O problema, porém, é que, se aprofundarmos a análise e diminuirmos o campo de intervenção dos instrumentos analíticos ao nível de espaços geográficos mais pequenos, então, com relativa facilidade, identificamos regiões inteiras com grandes problemas de inserção no mercado global, sem capacidade de concorrer nesses mesmos mercados. A imagem que obteremos do país não é igual à soma do que observamos região a região, de Norte a Sul, do litoral até à fronteira, nem se confunde com a média dos vários espaços geográficos.

Do ponto de vista das regiões deprimidas, o investimento para melhorar acessibilidades é importante, a construção de escolas e hospitais é fundamental, o incentivo à localização de empresas é imprescindível para o 
crescimento económico e a fixação das populações. Mas, quem determina o ritmo destes apoios? E a intensidade? Quem define os objectivos de desenvolvimento e as estratégias a seguir, quem enquadra os investimentos públicos? Não podemos esquecer que a história da política regional, entendida como política de intervenção centralizada do Estado em regiões deprimidas, é uma história de muitos insucessos, como atestam exemplos do Sul de Itália ou mesmo da França.

As regiões necessitam de todos aqueles meios que resultam da solidariedade nacional mas, antes de tudo, têm de possuir o seu próprio projecto, no sentido de darem resposta aos desafios da sua inserção no espaço nacional e também no mercado global. A primeira tarefa do Estado é, pois, a de proporcionar capacidade de organização às regiões. $O$ primeiro passo é deixar que elas assumam a sua identidade e organizem os seus projectos. Por isso se defende, também, a necessidade da Regionalização, enquanto processo capaz de permitir a criação de órgãos políticos geradores de dinâmicas próprias e mobilizadores de energias, iniciativas e projectos.

A estas regiões opõem-se as actuais "regiões-sindicato" que, sem estratégias nem políticas, reivindicam hoje uma auto-estrada, amanhã uma escola, no dia seguinte um estádio, etc., etc. sem objectivos nem rumo, numa lógica reivindicativa pura de algumas fatias mais do orçamento do Estado. A lógica de hoje, das "regiões que temos", é a lógica da soma nula, em que os ganhos de uns se traduzem em igual perda de outros. Tem sido esta, afinal, a prática do crescimento que permite que populações e actividades económicas continuem a "escorrer" de umas regiões para outras e as mais deprimidas se virem para Espanha, onde procuram serviços de educação ou de saúde, mas também emprego e investimento.

Ao contrário, as "regiões-projecto" que a Regionalização pode fazer surgir terão capacidades e meios para assumirem e apostarem nas suas diferenças, nos factores que identificam as suas vantagens absolutas e que contribuirão para a produção de valor acrescentado. É uma lógica de soma positiva em que os ganhos de cada região não representam perdas de outros, antes são construídos à custa de maior eficiência de organização e de aproveitamento de recursos ou em resultado da dinamização dos agentes locais em torno de projectos mobilizadores. 


\section{NOTAS}

1 “... raro será o país que não se debate com a existência de regiões-problema, sejam elas regiões sub-desenvolvidas, deprimidas ou congestionadas" (Lopes, 1980).

${ }^{2} \mathrm{O}$ artigo não pretende ser exaustivo nesta matéria, remetendo-se, por isso, para Porto (1988).

${ }^{3}$ Uma interessante síntese sobre estas questões pode encontrar-se no manual do economista canadiano Mario Polèse, sobre Economia Urbana e Regional, recentemente editado pela APDR - Associação Portuguesa para o Desenvolvimento Regional.

${ }^{4}$ Conhecido em muitos casos de "desenvolvimento endógeno". Pode afirmar-se que, mais do que uma construção teórica, este "modelo" é tão-só uma tentativa de sistematização dos resultados de diferentes situações vividas por diversas regiões ao longo dos anos 70 e 80 . Sendo situações geograficamente localizadas, não deixam por isso de constituir fenómeno generalizado por toda a Europa.

Em torno desta problemática, que é mais vasta e mais profunda do que estas breves referências deixam antever, sugere-se a leitura da obra editada recentemente de Kovács e Castillo (1998).

${ }^{5}$ Como deixámos subentendido acima, quando nos referimos a um "território" é um espaço geográfico, contextualizado por um conjunto mais vasto de territórios que constituem o todo nacional (ou europeu, se quisermos olhar o problema noutra perspectiva), e no qual existem recursos naturais, se desenvolvem actividades económicas, habitam pessoas com um saber e uma experiência próprios que lhe dão capacidade de gerir esses recursos e actividades numa situação de abertura a outros territórios e ao mundo. O território é, pois, um espaço aberto e dinâmico sujeito às intervenções de agentes internos, às influências de agentes exteriores.

${ }^{6}$ Primeira versão oficial provisória do Esquema de Desenvolvimento do Espaço Comunitário (EDEC), aprovado em reunião informal de ministros responsáveis pelo ordenamento do território dos Estados-Membros da U.E., em Noordwijk, em Junho de 1997.

7 Assinale-se, por paradigmática, a total descoordenação entre os serviços desconcentrados dos diversos ministérios que, nem abrangem, necessariamente, a mesma área geográfica nem, mesmo quando isso acontece, são coordenados horizontalmente, como se não fossem serviços do mesmo governo mas de "donos" autónomos, virados de costas uns para os outros, sem terem de responder de forma coordenada perante a região onde se localizam.

${ }^{8}$ Os municípios não têm dimensão para tal tarefa, os Distritos não representam as regiōes mas tão só o poder central e as comissões de coordenação têm meios humanos e capacidade técnica mas não têm legitimidade política e os meios financeiros são gerados a partir do orçamento do Estado, em função dos desígnios do governo central que não são necessariamente coincidentes com os desígnios da região.

${ }^{9}$ Que não toquem em questões ideológicas ou de natureza sensível para as populações de um ou outro concelho. 


\section{BIBLIOGRAFIA}

KOVÁCS, I. e CASTILlO, J. J. (1998), Novos modelos de Produção, Oeiras, Celta Editora.

LOPES, A. S. (1980), Desenvolvimento Regional, Lisboa, Fundação Calouste Gulbenkian.

POLÈSE, M. (1998), Economia Urbana e Regional, Coimbra, Associação Portuguesa para o Desenvolvimento Regional.

PORTO, M. (1988), Do Acto Único à "Nova Fronteira" para a Europa, Separata do ${ }^{\circ}$ especial do "Boletim da Faculdade de Direito de Coimbra" - "Estudos em Homenagem ao Prof. Doutor Afonso Rodrigues Queiro" - 1986.

SIMÕES, A. e MATOS, E. (1996), Regionalizar - Enquadramento de Viseu no Processo de Regionalização, Viseu, Airv. 